\title{
As leis de Diretrizes e Bases da Educação Brasileira e o Educador do Século XXI
}

\author{
Francizete Correia Amaro da Silva ${ }^{1}$; Maria Paula Silvestre Campelo ${ }^{2}$; Sidney Medeiros de Oliveira ${ }^{3}$
}

\begin{abstract}
Resumo: O presente artigo visa refletir acerca das Leis de diretrizes e Bases da Educação das décadas de 1960 e 1996, delineando a política educacional do século XXI para o educador. Desta forma, num primeiro momento, será explicitada uma breve fundamentação legal das referidas leis em suas respectivas décadas. Num segundo momento, será realizada uma análise comparativa das LDB’S de 1960 e 1996, e suas funções sociais, mostrando pontos importantes e as principais disposições legais que regulamentam o ensino. Por fim busca-se enfatizar a missão do educador diante dos paradigmas do século XXI, enquanto sujeitos que estão frente ás novas exigências que regem o profissional da educação brasileira. Desta forma o presente estudo traz luz a importantes momentos da história da educação e do profissional que forma cidadãos humanizados, que preparam o aluno para o futuro, mas que enxergam sua importância no presente, nesse âmbito a LDB frisa o desenvolvimento potencial de ambos professores e alunos de modo continuo e sistemático.
\end{abstract}

Palavras Chaves: LDB, educação para o século XXI, missão, professor.

\section{The Law of Guidelines and Bases of Brazilian Education and the Educator of the XXI Century}

\begin{abstract}
This article aims to reflect on the laws and guidelines of Basic Education in the 1960s and 1996 , outlining the educational policy for the twenty-first century educator. Thus, at first, will be outlined briefly legal foundation of those laws in their respective decades. Secondly, a comparative analysis of LDB 'S 1960 and 1996 , and its social functions will be held, showing important points and key law governing education . Finally we seek to emphasize the mission of the educator before the paradigms of the twelfth century, as subjects who are facing the new requirements governing the professional Brazilian education. Thus, the present study brings light to important moments in the history of education and professional manner humanized citizens , preparing students for the future, but they see its importance in the present context that the LDB emphasizes the potential development of both teachers and students continuously and systematically.
\end{abstract}

Key Words : LDB, education for the twenty-first century, mission, teacher

\section{Introdução}

O objetivo desse estudo foi de analisar a evolução da Lei que regulamenta o ensino brasileiro nos âmbitos histórico, legal, sociológico e conceitual; para compreender como foram constituídas até chegar ao contexto atual; visto que os principais dispositivos são as Leis de 1996 e de 1960.

\footnotetext{
${ }^{1}$ Graduada em História pela (URCA) Universidade Regional do Cariri. Especialista em História e Sociologia pela Universidade Regional do Cariri. Especialista em Metodologia e Docencia do Ensino Superior pela Faculdade Vale do Jaguaribe. franncyamaro@yahoo.com.br ${ }^{2}$ Graduada em Recursos Humanos pela Faculdade Leão sampaio, Mestranda em Ciências da Educação pela Universidade Lusófona de Lisboa - PT. E-mail: paulascampelo@hotmail.com;

${ }^{3}$ Licenciado em Educação Física pela Universidade Federal de Pernambuco, Doutorando em Ciências da Saúde pela Faculdade de Medicina do ABC. Professor Substituto no Instituto Federal do Ceará - Cedro-Ce.E-mail: sidneymeolli@ gmail.com
} 
O trabalho esta dividido em três partes. Na primeira parte, consta a fundamentação legal da LDB das décadas de 60 e 90, com suas regulamentações, reformas e os programas sociais que as norteiam.

Na segunda parte, busca-se analisar, conforme as referencias bibliográficas, as semelhanças e diferenças sociais de ambas as leis. Observando os caminhos, os embates e as divergências legais de ambas até sua regulamentação final. No terceiro tópico, será feita uma breve reflexão sobre a formação e atuação dos educadores do século XXI, bem como sua missão diante dos paradigmas que ilustram a sociedade vigente.

Posto que os progressos científicos, tecnológicos e econômicos relacionados a diferentes aspectos globais, provocam mudanças de toda ordem. Diante dessas mudanças o educador precisa implementar técnicas e competências cognitivas relacionadas a educação e as leis que regem o pais.

Assim por meio deste estudo poderá ser observada a importância das referidas Leis de Diretrizes e Bases da Educação para a comunidade escolar, pois a escola esta inserida em um contexto complexo, que ira redimensionar o modo de pensar e fazer educação; é uma instituição onde as relações, o conjunto da gestão cotidiana conspiram para instruir a atividade humana fundamentada em valores e aprendizagem.

\section{Fundamentação Legal da Lei de Diretrizes e Bases da Educação}

O sistema educacional brasileiro até 1960 era centralizado e o modelo era seguido por todos os estados e municípios. Com a aprovação da primeira Lei de Diretrizes e Bases da Educação (LDB), em 1961, os órgãos estaduais e municipais ganharam mais autonomia, diminuindo a centralização do MEC. Foram necessários treze anos de debate (1948 a 1961) para a aprovação da primeira LDB.

O ensino religioso facultativo nas escolas públicas foi um dos pontos de maior disputa para a aprovação da lei. O pano de fundo era a separação entre o Estado e a Igreja. O salário educação, criado em 1962, também é um fato marcante na história do Ministério da Educação. Até hoje, essa contribuição continua sendo fonte de recursos para a educação básica brasileira.

A reforma universitária, em 1968, foi a grande LDB do ensino superior, assegurando autonomia didático-científica, disciplinar administrativa e financeira às universidades. A reforma representou um avanço na educação superior brasileira, ao instituir um modelo organizacional único para as universidades públicas e privadas. 
A educação no Brasil, em 1971, se vê diante de uma nova LDB. O ensino passa a ser obrigatório dos sete aos 14 anos. O texto também prevê um currículo comum para o primeiro e segundo graus e uma parte diversificada em função das diferenças regionais.

Em 1985, é criado o Ministério da Cultura. Em 1992, uma lei federal transformou o MEC no Ministério da Educação e do Desporto e somente em 1995, a instituição passa a ser responsável apenas pela área da educação. Uma nova reforma na educação brasileira foi implantada em 1996. Trata-se da mais recente LDB, que trouxe diversas mudanças às leis anteriores, com a inclusão da educação infantil (creches e pré-escola).

A formação adequada dos profissionais da educação básica também foi priorizada com um capítulo específico para tratar do assunto. Ainda em 1996, o Ministério da Educação criou o Fundo de Manutenção e Desenvolvimento do Ensino Fundamental e de Valorização do Magistério (Fundef) para atender o ensino fundamental. Os recursos para o Fundef vinham das receitas dos impostos e das transferências dos estados, Distrito Federal e municípios vinculados à educação.

O FUNDEF vigorou até 2006, quando foi substituído pelo Fundo de Manutenção e Desenvolvimento da Educação Básica e de Valorização dos Profissionais da Educação (FUNDEB). Agora, toda a educação básica, da creche ao ensino médio, passa a ser beneficiada com recursos federais. Um compromisso da União com a educação básica, que se estenderá até 2020.

É nessa trajetória de quase 80 anos que o Ministério da Educação busca promover um ensino de qualidade. Com o lançamento do Plano de Desenvolvimento da Educação (PDE), em 2007, o MEC vem reforçar uma visão sistêmica da educação, com ações integradas e sem disputas de espaços e financiamentos. No PDE, investir na educação básica significa investir na educação profissional e na educação superior.

A construção dessa unidade só será possível com a participação conjunta da sociedade. Com o envolvimento de pais, alunos, professores e gestores, a educação se tornará um compromisso e uma conquista de todos.

Nas décadas de 60 e 90, considerando o nível de desenvolvimento da industrialização na América Latina, a política educacional vigente priorizou, como finalidade para o Ensino Médio, a formação de especialistas capazes de dominar a utilização de maquinarias ou de dirigir processos de produção. Essa tendência levou o Brasil a propor a profissionalização compulsória, estratégia que também visava a diminuir a pressão da demanda sobre o ensino superior.

Na década de 90, enfrentou-se um desafio de outra ordem. O volume de informações, produzido em decorrência das novas tecnologias, é constantemente superado, colocando novos parâmetros para a formação dos cidadãos. Não se trata de acumular conhecimentos.

Id en line Revista de Psicologia. Ano 8, No. 22, Fevereiro/2014 - ISSN 1981-1179. Edição eletrônica em http://idonline.emnuvens.com.br/id 
A formação do aluno deve ter como alvo principal a aquisição de conhecimentos, a preparação cientifica e a capacidade de utilizar as diferentes tecnologias relativas a área de atuação.

\section{Análise Comparativa das LDB’s de 1960 e 1996, e sua Função Social}

A princípio, as duas leis sucederam um período histórico no qual o Brasil era governado de forma repressiva, a primeira lei após o Estado Novo, e a nova e atual após o Regime Militar.

Tanto uma quanto a outra tiveram um processo motivado por interesses políticos e administrativos vinculado com a rede particular de ensino. Nenhuma, porém, foi totalmente voltada para as necessidades educacionais do país abrangendo as escolas públicas.

A longa tramitação, as grandes dificuldades de negociação, a morosidade e as vicissitudes do processo legislativo acabaram por levar a desgastes no processo de participação dos profissionais da educação, à diminuição de seu interesse e uma certa apatia relativamente à matéria. (TANURI, 1998, p.36)

Ao longo da história da LDB, apresentou-se uma série de manobras e até mesmo de sabotagem, sacrificando sua tramitação. O que levou treze anos para ser aprovado na primeira LDB, que vinha com a proposta de modificar a estruturação da educação brasileira, e a fim de democratizar o ensino, não durou nem três anos por conta do golpe militar que em 1964 desestruturou a nossa educação com seu regime ditatorial.

Cujos resultados são os que até hoje existe em quase todas as escolas: elevados índices de repetência e evasão escolar, escolas com deficiência de recursos materiais e humanos, professores pessimamente remunerados e sem motivação para trabalhar e elevadas taxas de analfabetismo (PILETTI, C.;PILETTI, N.,1997).

Momentos históricos de luta pela descentralização já eram assinalados, como o caso dos Pioneiros da Educação que apontavam a necessidade de uma ruptura com o centralismo, pois uma escola unitária não implica necessariamente em uniformidade. Na década de 40, com o fim do Estado Novo e nos momentos seguintes, em pleno período da ditadura militar, a descentralização foi discutida e a ela atribuía-se algumas especificidades como desburocratização.

Ao passar pelo rompimento da democracia, alguns ramos da educação tiveram uma transformação com as leis $\mathrm{n}^{\circ} 5.540$ e $\mathrm{n}^{\circ}$. 5.692, mas apenas para amenizar as reivindicações em torno da educação. 
Com a volta para a realidade democrática, findado o regime militar, propos-se uma nova lei para atender às necessidades que a época exigia, mas assim como a primeira LDB, esta também sofreu uma sabotagem com a interrupção do senador Darcy Ribeiro no projeto de Sabóia, tendo êxito as forças dos favores.

A primeira LDB (Lei de Diretrizes e Bases da Educação Nacional), Lei 4.024 de 20 de dezembro de 1961, tem duas referências ao termo "qualidade" A primeira,de maneira indireta, está no Título “Da Educação de Grau Médio”, no caput do Artigo 96:

O Conselho Federal de Educação e os Conselhos Estaduais da Educação na esfera de suas respectivas competências, envidarão esforços para melhorar a qualidade e elevar os índices de produtividade do ensino em relação ao seu custo (BRASIL, LEI DE DIRETRIZES E BASES DA EDUCAÇÃO NACIONAL, 1961).

O artigo diz que esse melhorar a qualidade se dá na elaboração de planos e aplicação de recursos a partir de dados estatísticos e estudando os custos do ensino público, ajustando-o ao melhor nível de produtividade. Aprendizagem e qualidade são duas das dimensões de maior destaque na nova LDB. Em vários momentos, de forma direta ou indireta, a Lei 9.394 trata da questão da frequência.

O tema principal dos projetos da LDB de 1961 foi variando conforme o andamento do processo. O projeto original de Clemente Mariani levantou o debate sobre a centralização e descentralização da educação, que estava sendo manipulada pelo governo através do MEC.

Após um perecer desfavorável de Gustavo Capanema o projeto foi arquivado e posteriormente extraviado. Carlos Lacerda retoma a proposta de se fazer uma lei de diretrizes e bases da educação nacional, levantando em seu substitutivo a questão da liberdade de ensino, que na verdade se traduzia na velha disputa entre católicos e liberais (VIEIRA, 2007).

Num primeiro momento, o projeto inicial da nova LDB procurava restabelecer a democratização, autonomia e qualidade da educação nacional, dando continuidade na questão descentralizadora do ensino público, travando uma batalha com os interesses da rede particular.

De início, o primeiro projeto de cada lei especificamente, carregava um caráter democrático abordando em seu conteúdo aspectos relevantes para a mudança do ensino, sendo sugeridos por educadores e pessoas envolvidas diretamente com a educação. Infelizmente, as pessoas com maior influência não estão realmente preocupadas com nosso sistema precário de ensino, visando o próprio benefício num jogo de interesses e favores, como no caso da nova lei, que em seu texto final ficou quase totalmente voltado para as escolas particulares.

NISKIER (1969) faz suas ressalvas ao texto da lei №. 4.024/61, pontuando suas qualidades como o espírito descentralizador administrativos e pedagógicos, a variedade de cursos e a flexibilidade

Id en line Revista de Psicologia. Ano 8, No. 22, Fevereiro/2014 - ISSN 1981-1179. Edição eletrônica em http://idonline.emnuvens.com.br/id 
dos currículos da lei, como exigências de uma política educacional que visa ao desenvolvimento integral da personalidade, dentro da dinâmica de uma sociedade democrática.

Com esta visão, o autor conclui que essas características da LDB desempenham uma papel preponderante com a autonomia dos sistemas estaduais, de cada estabelecimento de ensino. Quanto aos equívocos da mesma, ROMANELLI (1986) ressalta que a possibilidade de os Estados e os estabelecimentos anexarem disciplinas optativas ao currículo mínimo, foi apenas na legislação, pois naquela realidade as escolas continuaram compondo seu currículo de acordo com os recursos materiais dos quais elas já dispunham. A lei em essência nada mudou.

Em outro momento, NISKIER (1996) faz uma análise sobre a lei No. 9.394/96, ressaltando que a referida lei busca o pleno desenvolvimento da pessoa, e caracteriza um novo projeto para a educação. Também frisa a introdução de inovações na formação de educadores, o processo nacional de avaliação do rendimento escolar, em todos os níveis de ensino, as possibilidades de ampliar a escolaridade obrigatória para nove anos, a partir dos seis anos de idade, e de dividí-la em dois ciclos, abrir caminho para a educação à distância, entre outras.

ZANETTI (2010) reflete a estrutura fragmentária apresentada na Lei 9394/96 inviabiliza a idéia de sistema nacional de educação, pois nela as diretrizes não são contempladas, a articulação e coordenação entre os Sistemas de Ensino ficam restritas ao Poder Executivo, impossibilitando a participação dos segmentos organizados da sociedade civil. Além disso, a Educação de Jovens e Adultos, a Educação Profissional, a Educação Infantil e a Educação Especial recebem um tratamento desarticulado da educação escolar regular.

E assim a LDB acaba por gerar inúmeras discussões sobre o papel que esta exerce em âmbito nacional. Alguns autores a veem como um prodígio da democracia do país, já outros a classificam como um material que atende apenas alguns interesses da rede privada, principalmente depois do senador Darcy Ribeiro ter desprezado os projetos que foram democraticamente montados pelos relatores anteriormente mencionados.

Pela Emenda Constitucional, o Ensino Médio deixa de ser obrigatório para as pessoas, mas a sua oferta é dever do Estado, numa perspectiva de acesso para todos aqueles que o desejarem. A LDB reitera a obrigatoriedade progressiva do Ensino Médio, portanto, uma diretriz legal, ainda que não mais constitucional, e confere caráter de norma legal por meio do Art. 21.

A lei 9.9394-96 muda o cerne a identidade estabelecida para o Ensino Médio contida na referência anterior, a Lei n 5.692-1971 cujo $2^{\circ}$ grau se caracterizava por uma dupla função: prepara para o prosseguimento de estudos e habilitar para o exercício de uma profissão técnica. Na perspectiva da nova lei, o ensino médio deverá se vincular ao mundo do trabalho e a prática social. 


\section{A Missão do Educador diante dos Paradigmas do Século XXI.}

A missão do professor no século XXI é ter conhecimentos teóricos além das disciplinas a que se propõe ministrar e uma gama diversificada de práticas de ensino, além de desenvolver os conteúdos de modo contextualizado, globalizado e diversificado o suficiente para envolver os alunos num projeto de ensino aprendizagem capaz de despertar interesse e motivação.

Ser professor no século XXI é desenvolver práticas de ensino que atendam à diversidade dos processos de aprendizagem dos alunos contemplando às necessidades individuais num trabalho coletivo de construção de conhecimento.

Sabe-se que o professor sozinho não pode tudo, mas que, segundo Gomes (2005), com habilidade para gerenciar as diversas restrições ele pode tornar seu trabalho mais eficaz no dia-a-dia escolar. Para a escola de hoje precisa-se de um professor com conhecimento intelectual suficiente para dominar o conteúdo que precisa desenvolver e competências especiais para atuar em espaços tão diversos quanto seu público ouvinte possa oferecer.

Com a democratização do ensino a escola passou a abrigar alunos de diversos estratos sociais com bagagem sócio-cultural diferente e para atender essa clientela é preciso que o professor esteja atento as reais necessidades da comunidade para interferir com mais eficiência. Menezes (apud GENTILE, 2007, p. 34) diz: “a escola precisa rever sua missão e seu projeto pedagógico para atender a todos, com ou sem problemas socioeconômicos".

Para alcançar essa eficiência o professor precisa desenvolver habilidades e competências. Perrenoud (2000) define essa competência como capacidade de mobilizar diversos recursos cognitivos para enfrentar um tipo de situações. As competências profissionais de um professor podem ser desenvolvidas.

Perrenoud (2000) observa em professores mais experientes a competência valiosa de perceber os múltiplos processos que acontecem ao mesmo tempo em sua turma, apreendendo o essencial do que se passa com tranqüilidade.

$\mathrm{Na}$ perspectiva de uma escola mais eficiente para todos organizar e dirigir situações de aprendizagem despender energia e tempo e dispor das competências profissionais necessárias são características essenciais ao professor. O aprender contínuo é essencial e se concentra em dois pilares: a própria pessoa, como agente, e a escola, como lugar de crescimento profissional permanente.

Para uma educação voltada para a totalidade dos indivíduos da sociedade e baseada nos quatro pilares da educação contemporânea estabelecidos pela Organização das Nações Unidas para a Educação, a Ciência e a Cultura (UNESCO): aprender a ser, a fazer, a viver juntos e a conhecer, é preciso uma reforma do pensamento. A teoria do pensamento complexo proposto por Edgar Morin 
pode contribuir para esta proposta de ensino: o objetivo do pensamento complexo é ao mesmo tempo contextualizar e globalizar e aceitar o desafio da incerteza.

Só o pensamento complexo é capaz de reconhecer as incertezas do conhecimento, articular e organizar as informações. A educação do futuro deve saber cuidar desse princípio de unidade e diversidade humana em todas as esferas: individual, social e cultural.

No século XXI, segundo Morin (2006) o ser humano deverá ser visto em toda a sua complexidade bipolarizada e antagônica, isto é: sábio e louco, trabalhador e lúdico, empírico e imaginário, econômico e consumista, prosaico e poético. "A missão da educação do futuro é ensinar a compreensão entre as pessoas como condição e garantia de solidariedade intelectual e moral da humanidade". (MORIN, 2006, p. 93).

A ética da compreensão prevê a prática mental de auto-exame permanente, já que a compreensão das nossas fraquezas ou faltas é a via para a compreensão das do outro. A compreensão do outro requer a tolerância que supõe a aceitação da expressão das idéias, convicções e escolhas contrárias às suas

O professor deve trabalhar para esta humanização da humanidade desenvolvendo a ética da solidariedade, da compreensão, do respeito à diversidade individual promovendo a consciência antropológica, ecológica e espiritual da condição humana e para tanto precisa desenvolver a inteligência geral que favorece o pensamento complexo com um trabalho pedagógico de conteúdos interdisciplinares, contextualizados e globalizados.

Contribuindo nas reflexões sobre as competências necessárias ao professor para a educação do século XXI, propõe um perfil: professor reflexivo. É preciso identificar essas práticas de reflexão, que sempre existiram na profissão docente. Tentar identificá-las e construir as condições para que elas possam se desenvolver.

Este pode ser o caminho para a construção de formação contínua do professor, pois a formação não se dá apenas pelo professor individualmente, é uma ação coletiva que deve ser desenvolvida dentro da escola, como ambiente de formação e crescimento profissional contínuo.

O professor individualmente precisa estar envolvido nesse projeto, comprometido com seu crescimento profissional e a formação de uma identidade coletiva. Apesar de a escola estar organizada para favorecer a progressão das aprendizagens ainda está nas mãos do professor conceber e administrar situações-problemas ajustadas ao nível e às possibilidades dos alunos diante da diversidade e pluralidade de aprendizes existente nas salas de aula atuais.

O professor precisa oferecer desafios que estejam ao alcance do aluno, trabalhando assim na zona de desenvolvimento proximal (VIGOTSKY apud PERRENOUD, 2000). 
Isto é difícil porque a dificuldade da tarefa proposta depende da dinâmica do grupo e da estratégia coletiva criada que pode favorecer apenas os alunos mais dotados de recursos, marginalizando os demais. A competência do professor se estabelece na escolha de situaçõesproblema situadas ao nível médio do grupo e nas improvisações didáticas e ações reguladoras desenvolvidas pelo mesmo no decorrer do projeto.

O professor deve ter uma visão longitudinal dos objetivos do ensino em todo o programa de formação de um ciclo de aprendizagem, isto é, programas dos anos anteriores e posteriores. Este conhecimento proporciona ao professor saber inscrever cada aprendizagem em uma continuidade a longo prazo e contribuir para a construção das habilidades e competências visadas ao final de um ciclo ou da formação de um aluno.

\section{Conclusão}

Somente pedagogias diferenciadas podem atender a multiplicidade e elas devem desenvolver e promover a cooperação entre os alunos para um ensino mútuo, já que é impossível ao professor atender a todos ao mesmo tempo. O professor não deve ser a única fonte de impulso de aprendizagens, ele deve sim promover conflitos sócio-cognitivos (PERRET-CLERMOND apud PERRENOUD, 2000) que promovam atitudes de cooperação entre os alunos num trabalho em grupo de ensino mútuo

As perspectivas apontadas por este artigo estimulam a reflexão acerca da possibilidade de um país, com melhores estruturas de dimensões pedagógicas bem como na qualidade da educação. Nesse âmbito o suporte do educador seria cristalizado em sua formação e atuação profissional.

No que tange a Lei de Diretrizes e Bases da Educação, a Constituição de 1988 da Republica Federativa do Brasil e tantas outras leis que visam regimentar e integralizar seus objetivos e metas de forma democrática, existe a uma vertente de que pode ser construído a partir dessas bases legais um novo sistema educacional de qualidades impares.

A priori as funções sociais das referidas leis permitem o aperfeiçoamento dos profissionais da educação, das instituições de ensino bem como a integração entre sociedade e escola. Logo, a docência deve constituir-se parte integrante de uma política consciente, política, global, no intuito de valorizar e dignificar as estruturas educacionais como um todo. 


\section{Referências}

CASTILHO, Sylvia Amelia Giraldi. A formação do perfil do professor do século XXI / Sylvia Amélia Giraldi Castilho. -- Lins, 2009. 40p.il.31cm.

NISKIER, Arnaldo. Administração escolar. 1. ed. São Paulo: Tabajara, 1969. p. 74-79.

NISKIER, Arnaldo. LDB a nova lei da educação: tudo sobre a lei de diretrizes e bases da educação nacional: uma visão crítica. 7 ed. Rio de Janeiro: Consultor, 1997. p. 5-28.

PILETTI, Cláudino; PILETTI, Nelson. História da educação. 5 ed. São Paulo: Ática, 1997. p. 186225.

TANURI, Leonor. A nova LDB e a questão da administração educacional. In: MACHADO, Lourdes Marcelino; SILVA, Carmem Silvia Bissolli (orgs.). Nova LDB: trajetória para a cidadania? São Paulo: Arte \& Ciência, 1998. p. 30-39.

VIEIRA, Sofia Lerche. O público e o privado nas tramas da LDB. In: BRZEZINSKI, Iria (org.). LDB interpretada: diversos olhares se entrecruzam. 10 ed. São Paulo: Cortez, 2007. p. 69-82.

VILLALOBOS, João Eduardo Rodrigues. Diretrizes e bases da educação: ensino e liberdade. 1 ed. São Paulo: Editora da universidade de são Paulo, 1969. p. 220.

ZANETTI, Maria. Política educacional e LDB: algumas reflexões. Disponível em: <http://www.milenio.com.br/ifil/Biblioteca/zanetti.htm>; Acesso em 16 de outubro de 2010.

Como citar este artigo (Formato ISO):

SILVA, F.C.A.; CAMPELO, M.P.S.; OLIVEIRA, S.M. As leis de Diretrizes e Bases da EducaçãO Brasileira e o Educador do Século XXI. Id on Line Revista de Psicologia, Fevereiro de 2014, vol.8, n.22, p. 23-32. ISSN 1981-1189. 